\title{
Effects of Walnut Polyphenol on Learning and Memory Functions in Hypercholesterolemia Mice
}

\author{
Dandan Shi ${ }^{1}$, Chaoyin Chen ${ }^{1, *}$, Shenglan Zhao ${ }^{2}$, Feng Ge ${ }^{1}$, Diqiu Liu ${ }^{1}$, Hao Song ${ }^{1}$ \\ ${ }^{1}$ Faculty of life science, Kunming University of Science and Technology, Kunming, People's Republic of China \\ ${ }^{2}$ Yunnan University of Traditional Chinese Medicine, Kunming, People's Republic of China \\ *Corresponding author: chaoyinchen@163.com
}

Received June 05, 2014; Revised July 25, 2014; Accepted July 31, 2014

\begin{abstract}
Evidence suggests that dietary walnuts are able to induce improvements in memory and learning functions. In addition, polyphenols have been shown to modulate critical neuronal signalling pathways involved in processes of learning and memory. The aim of our present work was to study the effect of polyphenol extracts from walnut testa (42\%) on learning and memory functions in hypercholesterolemia mice based on obesity, hypercholesterolemia and oxidative stress. At the beginning of the experiment, mice were divided into 3 groups, one of them served as normol control group (NCG), the second as hypercholesterolemia control group (HCG), the last as walnut polyphenol-treated group (WTG). After 8 weeks of treatment, we investigated the performance of C57BL/6J mice in Morris water maze test. The results showed that the escape latency was significant increase in HCG, when compared to NCG and WTG. In addition, the number of crossings was significant decrease in HCG, when compared to NCG and WTG $(-47.35 \%$ and $-43.35 \%$, respectively, $\mathrm{P}<0.01)$. The swimming distance was longer in HCG than NCG and WTG $[\mathrm{F}(2,96)=44.45, \mathrm{P}<0.001]$. However, there was no significant difference in swimming speed among NCG, HCG and WTG [F $(2,96)=0.167, \mathrm{P}>0.05]$. On the other hand, walnut polyphenol (WP) significantly decreased serum total triglycerides, cholesterol and malondialdehyde (MDA) level $(-36.31 \%,-31.48 \%$ and $21.51 \%$, respectively, $\mathrm{P}<0.01)$ and increased superoxide dismutase (SOD) activity $(+48.39 \%, \mathrm{P}<0.01)$. Administration of WP significantly decreased MDA level $(-36.86 \%, \mathrm{P}<0.01)$ and increased SOD activity $(+17.08 \%, \mathrm{P}<0.01)$ in brain tissues. In conclusion, walnut polyphenol was able to improve learning and memory functions.
\end{abstract}

Keywords: walnut polyphenol, learning and memory functions, obesity, hypercholesterolemia, oxidative stress

Cite This Article: Dandan Shi, Chaoyin Chen, Shenglan Zhao, Feng Ge, Diqiu Liu, and Hao Song, "Effects of Walnut Polyphenol on Learning and Memory Functions in Hypercholesterolemia Mice." Journal of Food and Nutrition Research, vol. 2, no. 8 (2014): 450-456. doi: 10.12691/jfnr-2-8-4.

\section{Introduction}

Memory is the process by which a learning experience is maintained over time. A single memory can be recalled by presenting a proper stimulus [1]. A large number of evidence show that cardiovascular-associated risk factors play a key role in the development of learning and memory impairment [2]. The study has found that both obesity and high fat consumption are linked to learning and memory impairment $[3,4]$. On the other hand, recent findings indicate that hypercholesterolemia may induce short-term spatial memory impairments in mice [5]. This is supported by studies in vivo, which confirm a potential beneficial protecting effect via inhibiting the cholesterol synthesis and lowering the concentrations of cholesterol against memory impairments [6,7]. However, the exact mechanism of high blood cholesterol induce memory deficits is not known [8]. In addition, oxidative stress has been strongly concerned in the pathophysiology of learning and memory impairment [9]. Previous studies have demonstrated that hypercholesterolemia can increase the levels of oxygen free radicals by reacting with lipids and proteins to produce some oxidized substances, such as MDA and SOD [10,11]. The increased oxidative stress induced oxidative damage in many regions of brain. Experimental studies have clearly confirmed that atorvastatin and pitavastatin can improve learning and memory functions [12], but long-term use of drugs may cause some side effects. So, strong interest has focused on finding new natural substances, which improve learning and memory functions without side effects.

Dietary supplementation with fruits and vegetables has been shown to improve cognitive disorder, possibly through their biological activity $[13,14,15]$. Walnut has an abundant of significant nutrients that seem to have potential effects on human health [16]. Experimental studies found that a walnut diet could improve learning and memory functions $[17,18]$.

Polyphenols are the most abundant antioxidants in various food, including fruits, vegetables and nuts [19,20]. Previous researches have clearly found that polyphenols might protect from cognitive impairment due to their antioxidant [21,22]. Moreover, it has been reported that rutin and caffeine as antioxidant substances have 
beneficial effects on memory function [23,24]. Walnut is rich in polyphenols and contains numerous ellagitannins $[25,26]$, walnut polyphenol not only has antioxidant and anti-inflammatory activity but improves interneuronal signaling and increases neurogenesis $[27,28]$. In order to continue the previous research $[17,29]$, this research work was designed to determine whether treatment with walnut polyphenol could restore the memory impairment in hypercholesterolemia mice.

\section{Material and Methods}

\subsection{Extraction of Polyphenols}

WP was prepared as follows: dried walnut testa cultivated in china were powdered and extracted at $60^{\circ} \mathrm{C}$ for $1 \mathrm{~h}$ with $50 \%(\mathrm{v} / \mathrm{v})$ ethanol (solid-liquid ratio, 1:10), the solvent was subsequently evaporated. Then, the concentrates were formulated as $20 \mathrm{mg} / \mathrm{g}$ solution.

\subsection{Determination of Total Polyphenol Content}

The total polyphenol content of walnut extracts was measured according to a slightly modified Folin-Ciocalteu colorimetric method. Briefly, $1.0 \mathrm{~mL}$ of sample or solvent blank, was mixed with $5.0 \mathrm{~mL}$ of the Folin-Ciocalteu reagent (1:10) and $4.0 \mathrm{~mL}$ of $\mathrm{Na}_{2} \mathrm{CO}_{3}$ (7.5\% aqueous solution). The mixture was shaked up at room temperature for $60 \mathrm{~min}$. Absorption was measured at $765 \mathrm{~nm}$ in an Ultrospec 2100 spectrophotometer (UV-Vis, Amersham Biosciences). A standard curve was generated with gallic acid standard substance (concentration ranged from 10 to $70 \mu \mathrm{g} / \mathrm{mL}$ ). The calibration curve equation was $\mathrm{y}=0.1062 \mathrm{x}$ +0.0144 and had a correlation coefficient of $\mathrm{R}^{2}=0.9991$. WP was evaluated at a final content of $420 \mathrm{mg} / \mathrm{g}$. The total phenolic contents were expressed as percentages (\%) or milligrams per gram (gallic acid equivalents).

\subsection{Preparation of High Fat Diet (HFD)}

The HFD was prepared daily. It includes $83.25 \%$ standard diet, 10\% lard, 1.5\% cholesterol, 0.2\% NaTDC, 5\% Sugar and 0.05\% Propylthiouracil [30].

\subsection{Animals and Treatments}

Twenty-seven female C57BL/6J mice were housed in Animal Experimental Center with a pathogen-free environment on a 12-h light/ dark cycle and free access to food and water. Animal experiments were carried out in compliance with the standards for use of laboratory animals. After a 2-week adaptation period, animals were randomly divided into 3 groups. One of them served as normal control group (NCG): kept on standard diet and daily gavaged with normal saline. The second as hypercholesterolemia control group (HCG) : received HFD and daily gavaged with normal saline. The third as WP-treated group (WTG): received HFD and daily gavaged with WP at a dose of $200 \mu \mathrm{g} / \mathrm{g}$ body weight for 8 weeks.

\subsection{Morris Water Maze Test}

The Morris water maze consisted of a circular pool with a white underside and black side surface, a white platform, a camera and a computer. The pool was made of circular galvanized steel pool (1.2 m diameter, $0.5 \mathrm{~m}$ height) filled with water $\left(20-22^{\circ} \mathrm{C}\right)$. A white platform (8 cm diameter) was placed in the middle of one quadrant and submerged 1 $\mathrm{cm}$ below the surface of the water. A camera situated above the pool was used to capture the mice's swim trace. A computer was used to analysis data.

Mice were trained on water maze with four trials for $5 \mathrm{~d}$. At the begin of 0 day, mice was allowed to freely search platform with four trials. From the first day to the fourth day, the mouse was given four trials, a trial lasted $60 \mathrm{~s}$ or until the mouse reached the platform and remained a few seconds. If a mouse didn't reach the platform in $60 \mathrm{~s}$, it meant that its escape latency was $60 \mathrm{~s}$, then the mouse was allowed to rest for $30 \mathrm{~s}$ between trials. On the fifth day, the platform was removed and mice were tasked with a probe trial for 2 min [31,32].

\subsection{Lee's Index}

Mice were weighed in $\mathrm{g}(\mathrm{w})$ and the head to rump length measured in $\mathrm{cm}(\mathrm{r})$. the Lee's index was calculated as : Lee's index $=\mathrm{w}^{1 / 3} \times 10^{3} / \mathrm{r}$.

\subsection{Collection of Blood and Tissues}

Mice were anesthetized by subcutaneous injection of $0.1 \mathrm{mg} / \mathrm{g}$ body weight ketamine and $0.02 \mathrm{mg} / \mathrm{g}$ body weight xylazine, and blood was drawn from the retroorbital plexus. The blood samples were immediately centrifuged (3000 rpm/15 min) at $4{ }^{\circ} \mathrm{C}$ and the serum was used for lipid analysis.

Livers were removed, rinsed in ice-chilled normal saline and blotted on filter paper, the tissues were stored at $-20^{\circ} \mathrm{C}$ before used.

\subsection{Biochemical analysis}

The levels of serum total cholesterol (TC) were determined by cholesterol oxidase enzymatic method using the corresponding diagnostic kits (Nanjing Jiancheng Bioengineering Institute, Nanjing, PR China). cholesterol was hydrolyzed and in the presence of phenol, the quinoneimine as indicator was formed from hydrogen peroxide and 4-aminoantipyrine via peroxidase catalysis and was spectrophotometrically measured at $510 \mathrm{~nm}$ [33]. Total triglycerides (TG) were also quantified by enzymatic method using the corresponding diagnostic kits. Briefly, after enzymatic hydrolysis with lipases, the formation of quinoneimine from hydrogen peroxide, 4aminophenazone, and 4-chlorphenol under the catalytic effect of peroxidase was spectrophotometrically measured at $546 \mathrm{~nm}$ [33].

The assay for total SOD was based on its ability to inhibit the oxidation of hydroxylamine by the xanthinexanthine oxidase system [34,35]. SOD activity was measured at $550 \mathrm{~nm}$ by testing the inhibition degree of nitrite formation according to SOD detecting kit. One unit of SOD is defined as the enzyme required to produce 50\% inhibition of pyrogallol auto-oxidation, and date were expressed as units per milliliter of serum protein. MDA is produced during lipid peroxidation and can be determined by the thiobarbituric acid (TBA) test [23,34]. MDA 
reacted with TBA to form MDA-(TBA) $)_{2}$, a red-colored product with maximum absorbance at $532 \mathrm{~nm}$. MDA content was expressed as nanomoles per milliliter of serum protein.

\subsection{Preparation of Brain Tissues and Homogenates}

To measure biochemical indicators, the brain tissues were removed and the tissues containing cerebral cortex and hippocampus were immediately dissected and homogenized according to a previously described method [36]. The homogenate was centrifuged $3500 \mathrm{~g}$ at $4^{\circ} \mathrm{C}$ for $15 \mathrm{~min}$ and the supernatant was used for biochemical analysis.

\subsection{Measurement of SOD and MDA in Brain Tissues}

The activity of SOD in brain tissues of C57BL/6J mice was detected by a total SOD assay kit according to the manufacturer's protocol [34,35]. Briefly, brain extracts, nitroblue tetrazolium, and enzyme-working solutions were prepared and added into a 96-well plate. The mixtures were incubated at $37^{\circ} \mathrm{C}$ for $40 \mathrm{~min}$, and then the absorbance was assayed at $550 \mathrm{~nm}$ using an MD-M5 microplate reader (Molecular Devices Corporation, Manlo Park, CA, USA). For MDA measurement, the brain extracts were added to the detection solution of MDA in eppendorf tubes and then boiled for $40 \mathrm{~min}$. After centrifugation at $4000 \mathrm{rpm} / \mathrm{min}$ for $10 \mathrm{~min}$, the supernatant was collected in a 96-well plate and then determined using an MD-M5 microplate reader at $532 \mathrm{~nm}$ $[23,34]$.

\subsection{Statistical Analysis}

Statistical analysis was performed with the use of SPSS software (version 19.0, Chicago, IL, USA) and Origin 9.0. All data in this paper were expressed as mean \pm SD. The Morris water maze platform training data were analysed by two-way ANOVA. The other statistical significance of experimental observations was determined by one-way ANOVA. Statistical significance was set at $\mathrm{P}<0.05$.

\section{Results}

\subsection{Effect of WP on Body Weight Gain, Food Intake and Lee's Index}

The body weight gain in mice fed a high-fat diet was increased by $20.18 \%$ compared to mice fed a standard diet as shown in Table $1(\mathrm{P}<0.05)$. In the case of HFD, the body weight gain in WP-treated mice was decreased by $13.52 \%$ compared to mice fed a HFD (Table 1 ). As shown in Table 1, there was no remarkably difference in food intake (1760.2-1823.3 g). On the other hand, there were significant changes in Lee's index (308.03-330.76) among 3 groups.

Table 1. Body weight gain, food intake and Lee's index of mice

\begin{tabular}{cccc} 
& \multicolumn{2}{c}{ Table 1. Body weight gain, food intake and Lee's index of mice } & WTG \\
\cline { 2 - 4 } & NCG & HCG & $15.47 \pm 0.09$ \\
Initial body weight (g) & $15.46 \pm 0.14$ & $15.54 \pm 0.13$ & $22.97 \pm 0.47^{* *}$ \\
Final body weight (g) & $22.1 \pm 0.33^{* *}$ & $26.56 \pm 0.41$ & $7.5 \pm 0.51^{* *}$ \\
Body weight gain (g) & $6.64 \pm 0.41^{* *}$ & $11.02 \pm 0.47$ & $1760.02 \pm 28.91$ \\
Total food intake (g/ & $1823.3 \pm 26.41$ & $1779.05 \pm 27.57$ & $310.48 \pm 3.21^{* *}$ \\
Lee's index & $308.03 \pm 3.87^{* *}$ & $330.76 \pm 5.71$ &
\end{tabular}

The values were measured after $8 \mathrm{w}$ for feeding. Data are means \pm SD for 9 mice. ${ }^{*} \mathrm{P}<0.05$, ** $\mathrm{P}<0.01$ versus HCG.

\subsection{WP Attenuates Spatial Memory Deficits in Hypercholesterolemia Mice}

To assess spatial learning ability, mice were trained with 4 trials per day for $4 \mathrm{~d}$ on the Morris water maze test. Repeated-measures ANOVA revealed that the escape latency was affected by training day $[\mathrm{F}(3,96)=45.211$, $\mathrm{P}$ $<0.001]$ and treatment $[\mathrm{F}(2,96)=34.08, \mathrm{P}<0.001]$. However, the escape latency was not affected by their interaction $[\mathrm{F}(6,96)=1.954, \mathrm{P}>0.05]$. As shown in Figure 1A, the escape latency to locate the platform gradually decreased in all groups during the training period. However, the average escape latency for each group was as follow: HCG > WTG > NCG. The results also indicated that the average escape latency in HCG was significantly longer than that in NCG and WTG $(\mathrm{P}<0.05$, $\mathrm{P}<0.01)$.

Similarly, the swimming distance was affected by traning day $[\mathrm{F}(3,96)=77.884, \mathrm{P}<0.001]$ and treatment $[\mathrm{F}(2,96)=44.45, \mathrm{P}<0.001]$. However, the escape latency was not affected by their interaction $[\mathrm{F}(6,96)=2.619, \mathrm{P}>$ 0.05]. The average swimming distance was longer in HCG than NCG and WTG $(\mathrm{P}<0.05$ or $\mathrm{P}<0.01$; Figure $1 \mathrm{~B})$. There was also no significant difference in swimming distance between NCG and WTG. Moreover, the swimming speed was affected by trainning day $[\mathrm{F}(3,96)=$ $2.461, \mathrm{P}<0.01]$, but not by treatments $[\mathrm{F}(2,96)=0.167$, $\mathrm{P}>0.05]$. These results indicated that obesity did not affect the swimming ability among each group (Figure 1C).

On the fifth day, the platform was removed, and mice were given 2 min to search the missing platform for the probe trial. Data showed that the number of platform crossings by the HFD-treated mice was significantly lower than that by the normal mice (1.49 vs 2.83 , $\mathrm{P}<0.01)$. However, administration of WP significantly increased the number of platform crossings when compared to the HCG (2.63 vs $1.49, \mathrm{P}<0.01$, Figure 2). Overall, the results showed that WP could significantly improve memory function in hypercholesterolemia mice. 

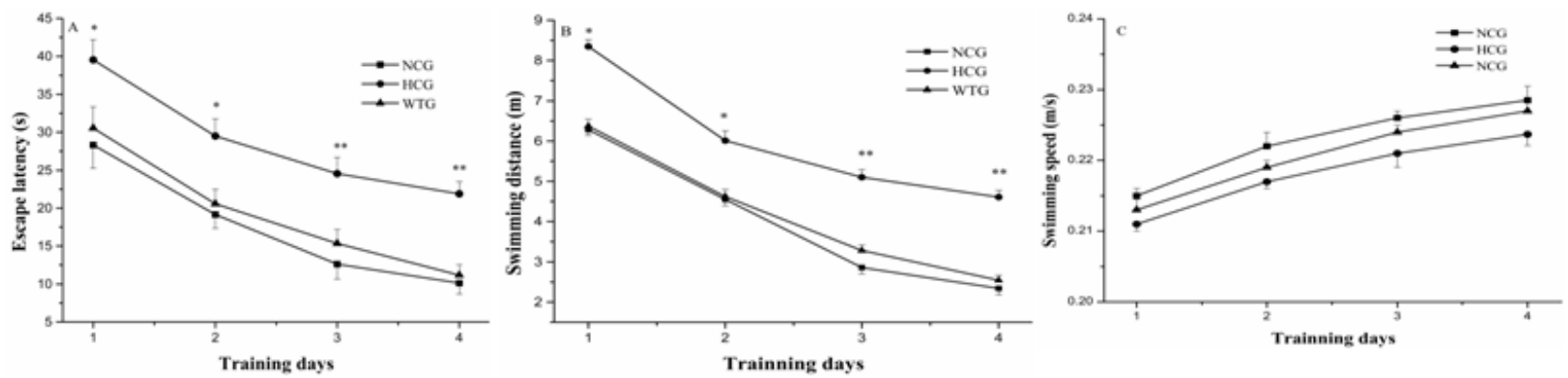

Figure 1. Effects of WP on spatial learning and memory in the Morris water maze. (A and B and C) Escape latency and swimming distance and swimming speed in the hidden platform test. The values were showed as mean \pm SD. $\mathrm{n}=9$ per group. ${ }^{*} \mathrm{P}<0.05, * * \mathrm{P}<0.01$ versus HCG

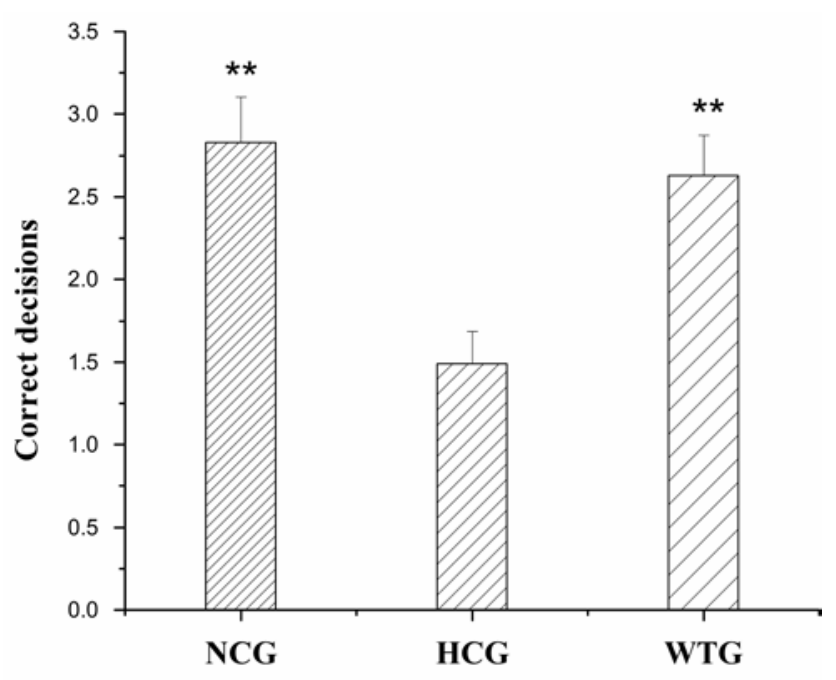

Figure 2. Effects of WP on number of crossings (the mice crossed the position where the platform was placed during learning sessions). Results were expressed as mean \pm SD of 9 animals per group. ${ }^{* *} \mathrm{P}<$ 0.01 versus HCG

\subsection{Effects of WP on the Serum Biochemical Indicators in Hypercholesterolemia Mice}

As shown in Figure 3A, the levels of TG and TC in HCG (137.5.24 \pm 8.7 and $243.78 \pm 9.31 \quad \mathrm{mg} / \mathrm{dl})$ were significantly higher than those in NCG $(76.24 \pm 3.76$ and $152.02 \pm 6.21 \mathrm{mg} / \mathrm{dl})(+80.35 \%$ and $+60.36 \%$, respectively, $\mathrm{P}<0.01$ ). However, WP administration significantly lowered the levels of TG and TC $(87.57 \pm 7.45$ and $167.03 \pm 3.84 \mathrm{mg} / \mathrm{dl})$ with respect to HCG $(-36.31 \%$ and $31.48 \%$, respectively, $\mathrm{P}<0.01$, Figure $3 \mathrm{~A}$ ).

In addition, it was observed that there was a significant increase in the level of MDA $(4.51 \pm 0.30 \mathrm{nmol} / \mathrm{mL})$ but a significant decrease in the activity of SOD $(98.42 \pm 4.17$ $\mathrm{U} / \mathrm{mL}$ ) in serum of mice in HCG, comparison with those of mice in NCG $(3.42 \pm 0.38 \mathrm{nmol} / \mathrm{mL}, 149.67 \pm 9.63 \mathrm{U} / \mathrm{mL})$ $(+31.87 \%$ and $-32.24 \%$, respectively, $\mathrm{P}<0.01$, Figure 3B and Figure 3C). Compared with HCG, WP administration significantly inhibited the synthesis and accumulation of MDA $(3.54 \pm 0.35 \mathrm{nmol} / \mathrm{mL})(-21.51 \%, \mathrm{P}<0.01)$, while the activity of SOD $(146.05 \pm 11.18 \mathrm{U} / \mathrm{mL})$ was significant increase $(+48.39 \%, \mathrm{P}<0.01)$.
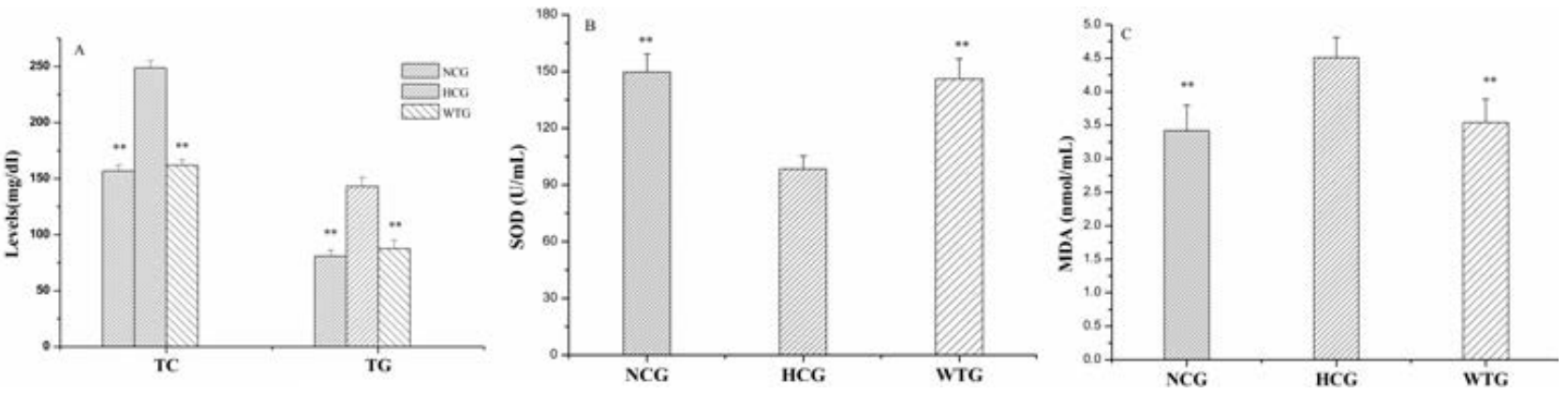

Figure 3. Effects of WP on the serum biochemical indicators in hypercholesterolemia mice. (A) Effects of WP on the levels of serum TC and TG; (B) Effects of WP on the activity of SOD in hypercholesterolemia mice; (C) Effects of WP on the activity of MDA in hypercholesterolemia mice.The values were showed as mean $\pm \mathrm{SD}$. $\mathrm{n}=9$ per group. ${ }^{* *} \mathrm{P}<0.01$ versus $\mathrm{HCG}$
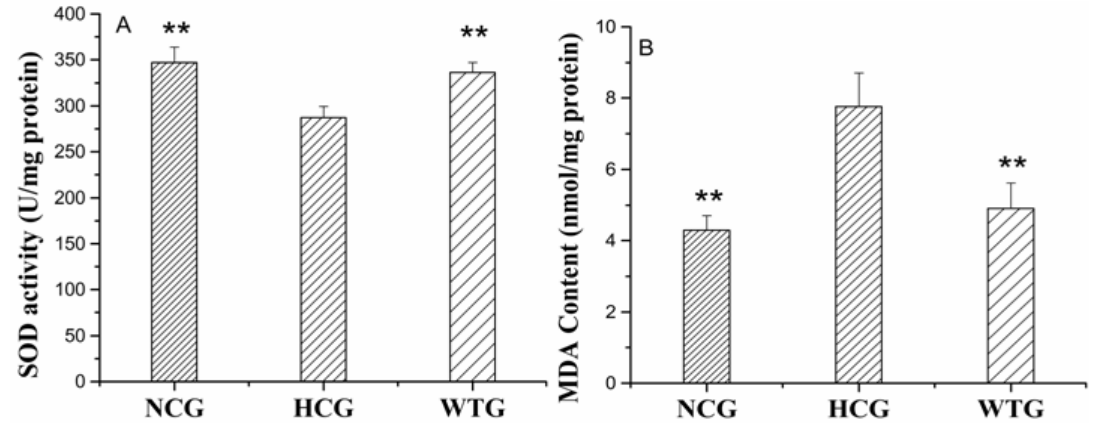

Figure 4. Effects of WP on brain oxidative statue of HFD-fed groups. (A) Effects of WP on the activity of SOD in hypercholesterolemia mice brain. (B) Effects of WP on the level of MDA in hypercholesterolemia mice brain. All data were expressed as mean \pm SD of nine animals per group. ${ }^{* *} \mathrm{P}<0.01$ versus HCG 


\subsection{Effects of WP on Brain Oxidative Statue of HFD-fed Groups}

As shown in Figure 4, there was a decrease in the activity of SOD $(-17.2 \%, \mathrm{P}<0.01)$ and an increase in the level of MDA in hypercholesterolemia mice brain. (+83.45\%, $\mathrm{P}<0.01)$. In addition, WP treatment could significantly increase SOD activity $(+17.08 \%, \mathrm{P}<0.01$, Figure $4 \mathrm{~A})$ and decrease MDA level $(-36.86 \%, \mathrm{P}<0.01$, Figure 4B) with respect to HCG.

\section{Discussion}

Obesity and hypercholesterolemia and oxidative stress play a pivotal role in the development of learning and memory impairment $[4,8,9]$. Long-term use of high fat diet or high energy diet could induce obesity and affect serum lipid levels and oxidative stress, which in turn affect learning and memory functions [37,38,39]. The traditional Mediterranean-style diet has fewer meats and carbohydrates and more plant-based foods and monounsaturated fat than a typical American diet. Following the traditional Mediterranean-style diet may lower incidence and prevalence of learning and memory functions ${ }^{[40,41]}$. In this regard, correlational studies have confirmed that polyphenols contribute to the prevention and treatment of learning and memory impairment [42,43]. Polyphenol extracts from walnut testa contained abundant polyphenols [26], we aimed to assess its beneficial effect on learning and memory functions after chronic HFD treatment in HFD-fed mice model.

Establishing hypercholesterolemia animal models according to the experience of workers $[44,45]$. In this experiment, similar results were found [46]: the HFD-fed mice have higher levels of TC than control group indicating that the hypercholesterolemia model was successfully established.

In recent years, several lines of evidence have shown that obesity is likely a major cause of the learning and memory impairment [47,48]. Although the accurate mechanism by which obesity results in learning and memory impairment is uncertain, some researchers have found that triglycerides impair the $\mathrm{N}$-methyl-d-aspartate (NMDA)-mediated maintenance of hippocampal longterm synaptic potentiation in obese mice. Hippocampal is considered as a neurophysiological correlate of learning and memory [48]. In this paper, the result shown that HFD could cause obesity and accumulation of triglycerides, and WP could inhibit obesity and decrease the level of triglycerides.

Oxidative stress is an important factor to the development of learning and memory impairment, which is known as the state of imbalance between the antioxidant level and the production of free radicals that induces the brain damage. Oxygen free radicals are easy to accumulate in the brain because of its high oxygen content, high level of polyunsaturated fatty acids and low antioxidant defense level [49]. Overproduction of free radicals will attact biological macromolecules, such as protein and nucleic acid functions, and can change their functions and induce lipid peroxidation, leading to cell death [50]. Oxygen free radicals can be scavenged by antioxidants including SOD. MDA is a by-product of lipid peroxidation and is widely used as a biomarker of oxidative stress [51]. In recent years, some researchers have found that Walnuts contain a number of potentially neuroprotective substances such as flavonoids and numerous polyphenolics which have both antiinflammatory and antioxidant properties and and it is shown that consumption of these compounds has a protective role against cisplatin-induced neurotoxicity without altering its anti-tumor activity [52,53]. An earlier study reported that Polyphenolic compounds found in walnuts not only reduce the oxidant and inflammatory load on brain cells but also improve interneuronal signaling, increase neurogenesis, and enhance sequestration of insoluble toxic protein aggregates [54]. In addition, Mohammad Shabani et al. have found that walnut consumption might have a protective effect against neurotoxic injury in rat brain and it can maintain purkinje cells in normal morphology and attenuate neural changes in hippocampus [55,56]. In this study, the activities of SOD in serum and brain tissues both showed a significant decrease in HFD-treated mice compared to normal mice. However, the levels of MDA in serum and brain tissues both showed a significant increase in HFD-treated mice compared to normal mice. Treatment with WP for 8 weeks could significantly improve the activities of SOD and decrease the levels of MDA in serum and brain tissues. Therefore, WP scavenged oxygen free radicals mainly via decreasing the level of MDA and increasing the activity of SOD.

In addition, several lines of evidence have confirmed that hypercholesterolemia affects oxidative stress and $\mathrm{A} \beta$ in animal and shows some neuropathological changes similar to those seen in memory disorders [8,57]. Epidemiological studies suggest that high level of cholesterol increases $A \beta$ generation and inhibits $\alpha$ secretase via activation of both $\beta$ - and $\gamma$-secretases and that hypercholesterolemia increases $A \beta$ levels in the brain [58]. The increased $A \beta$ and $A \beta$ aggregates induced the generation of oxygen free radicals and contributed to learning and memory impairment [23]. In this study, the level of cholesterol was significant increase in HFDtreated mice when compared to normal mice and WPtreated mice. Therefore, WP improved learning and memory functions may via improving lipid metabolism.

In this paper, we found that mice in HCG learnt the Morris water maze test more slowly than normal mice, and mice in WTG learnt the Morris water maze test more quickly than HCG. Furthermore, the swimming distance was longer in HCG than NCG and WTG. However, there was no significant difference in swimming speed among NCG, HCG and WTG. So, obesity and hypercholesterolemia and oxidative demage may affect learning and memory functions in hypercholesterolemia mice.

\section{Conclusion}

Diet-induced hypercholesterolemia in C57BL/6J mice caused learning and memory impairment, which was caused by obesity and hypercholesterolemia and oxidative stress. Our findings suggested that WP improved learning and memory functions mainly via decreasing body weight, hypercholesterolemia and oxidative demage. In addition, 
several evidence have confirmed that walnut may be beneficial in guarding against learning and memory impairment $[17,18]$. Collectively, our results provided an important basis on the prevention and treatment of learning and memory impairment.

\section{Acknowledgments}

Our thanks for the financial support of state science and technology support program and the science and technology major program of Yunnan education bureau.

\section{Statement of Competing Interests}

None.

\section{List of Abbreviations}

HFD: high fat diet, NCG: normol control group, HCG: hypercholesterolemia control group, WTG: walnut polyphenol-treated group, MDA: malondialdehyde, SOD: superoxide dismutase, TC: total cholesterol, TG: total triglycerides

\section{References}

[1] Thompson, R.F., \& Kim, J.J., Memory systems in the brain and localization of a memory. Proceedings of the national academy of sciences, 93 (24), 13438-13444, 1996.

[2] Evola, M., Hall, A., Wall, T., Young, A., Grammas, P., Oxidative stress impairs learning and memory in apoE knockout mice. Pharmacology biochemistry and behavior, 96 (2), 181-186, 2010.

[3] Moy G.A, McNay E.C., Caffeine prevents weight gain and cognitive impairment caused by a high-fat diet while elevating hippocampal BDNF. Physiology \& behavior, 109: 69-74, 2013.

[4] Farr, S.A., Yamada, K.A., Butterfield, D.A., Abdul, H.M., Xu, L., Miller, N.E., \& Morley, J.E., Obesity and hypertriglyceridemia produce cognitive impairment. Endocrinology, 149 (5), 2628-2636, 2008.

[5] Moreira, E.L.G., de Oliveira, J., Engel, D.F., Walz, R., de Bem, A.F., Farina, M., Prediger, R.D.S., Hypercholesterolemia induces short-term spatial memory impairments in mice: up-regulation of acetylcholinesterase activity as an early and causal event?. Journal of neural transmission, 1-12, 2013.

[6] Solomon, A., Kivipelto, M., Wolozin, B., Zhou, J., Whitmer, R.A., Midlife serum cholesterol and increased risk of Alzheimer's and vascular dementia three decades later. Dementia and geriatric cognitive disorders, 28 (1), 75-80, 2009.

[7] Rea, T.D., Breitner, J.C., Psaty, B.M., Fitzpatrick, A.L., Lopez, O.L., Newman, A.B., Kuller, L.H., Statin use and the risk of incident dementia: the Cardiovascular Health Study. Archives of neurology, 62 (7), 1047-1051, 2005.

[8] Ullrich, C., Pirchl, M., Humpel, C., Hypercholesterolemia in rats impairs the cholinergic system and leads to memory deficits. Molecular and cellular neuroscience, 45 (4), 408-417, 2010.

[9] Evola, M., Hall, A., Wall, T., Young, A., \& Grammas, P., Oxidative stress impairs learning and memory in apoE knockout mice. Pharmacology biochemistry and behavior, 96 (2), 181-186, 2010.

[10] Ben Khaled, H., Ghlissi, Z., Chtourou, Y., Hakim, A., Ktari, N., Fatma, M. A., Nasri, M., Effect of protein hydrolysates from sardinelle $(<i>$ Sardinella aurita $</ i>)$ on the oxidative status and blood lipid profile of cholesterol-fed rats. Food research international, 45 (1), 60-68, 2012.

[11] Prasad K., Vitamin E and regression of hypercholesterolemiainduced oxidative stress in kidney. Molecular and cellular biochemistry, 385 (1-2): 17-21, 2014
[12] Kurata, T., Miyazaki, K., Kozuki, M., Panin, V.L., Morimoto, N., Ohta, Y., Abe, K., Atorvastatin and pitavastatin improve cognitive function and reduce senile plaque and phosphorylated tau in aged APP mice. Brain research, 1371, 161-170, 2011.

[13] Shukitt-Hale, B., Cheng, V., Joseph, J.A., Effects of blackberries on motor and cognitive function in aged rats. Nutritional neuroscience, 12 (3), 135-140, 2009.

[14] Ye, X., Bhupathiraju, S.N., Tucker, K.L., Variety in fruit and vegetable intake and cognitive function in middle-aged and older Puerto Rican adults. British journal of nutrition, 109 (03), 503-510, 2013.

[15] Spencer, J.P., The impact of fruit flavonoids on memory and cognition. British journal of nutrition, 104 (S3), S40-S47, 2010.

[16] Savage G.P., Chemical composition of walnuts (Juglans regia L.) grown in New Zealand. Plant foods for human nutrition, 56 (1): 75-82, 2001.

[17] Haider, S., Batool, Z., Tabassum, S., Perveen, T., Saleem, S., Naqvi, F., Haleem, D.J., Effects of walnuts (Juglans regia) on learning and memory functions. Plant foods for human nutrition, 66 (4), 335-340, 2011.

[18] Willis, L.M., Shukitt-Hale, B., Cheng, V., Joseph, J.A., Dosedependent effects of walnuts on motor and cognitive function in aged rats. British journal of nutrition, 101 (08), 1140-1144, 2009.

[19] Rodrigo, R., Miranda, A., Vergara, L., Modulation of endogenous antioxidant system by wine polyphenols in human disease. Clinica chimica acta, 412 (5), 410-424, 2011.

[20] Quideau, S., Deffieux, D., Douat - Casassus, C., Pouységu, L., Plant polyphenols: chemical properties, biological activities, and synthesis. Angewandte chemie international edition, 50 (3), 586621, 2011.

[21] Xu, Y., Zhang, J.J., Xiong, L., Zhang, L., Sun, D., Liu, H., Green tea polyphenols inhibit cognitive impairment induced by chronic cerebral hypoperfusion via modulating oxidative stress. The journal of nutritional biochemistry, 21 (8), 741-748, 2010.

[22] Fernández-Fernández, L., Comes, G., Bolea, I., Valente, T., Ruiz, J., Murtra, P., Unzeta, M., LMN diet, rich in polyphenols and polyunsaturated fatty acids, improves mouse cognitive decline associated with aging and Alzheimer's disease. Behavioural brain research, 228 (2), 261-271, 2012.

[23] Xu, P.X., Wang, S.W., Yu, X.L., Su, Y.J., Wang, T., Zhou, W.W., Liu, R.T., Rutin improves spatial memory in Alzheimer's disease transgenic mice by reducing $A \beta$ oligomer level and attenuating oxidative stress and neuroinflammation. Behavioural brain research, 264, 173-180, 2014.

[24] Leite, M.R., Wilhelm, E.A., Jesse, C.R., Brandão, R., Nogueira, C.W., Protective effect of caffeine and a selective $A_{2 A}$ receptor antagonist on impairment of memory and oxidative stress of aged rats. Experimental gerontology, 46 (4), 309-315, 2011.

[25] Li, L., Tsao, R., Yang, R., Liu, C., Zhu, H., Young, J.C., Polyphenolic profiles and antioxidant activities of heartnut (Juglans ailanthifolia var. cordiformis) and Persian walnut (Juglans regia L.). Journal of agricultural and food chemistry, 54 (21), 8033-8040, 2006.

[26] Ito, H., Okuda, T., Fukuda, T., Hatano, T., Yoshida, T., Two novel dicarboxylic acid derivatives and a new dimeric hydrolyzable tannin from walnuts. Journal of agricultural and food chemistry, 55 (3), 672-679, 2007.

[27] Poulose, S.M., Miller, M.G., \& Shukitt-Hale, B., Role of walnuts in maintaining brain health with age. The journal of nutrition, 144 (4), 561S-566S, 2014

[28] Joseph, J., Cole, G., Head, E., Ingram, D., Nutrition, brain aging, and neurodegeneration. The journal of neuroscience, 29 (41), 12795-12801, 2009.

[29] Letenneur, L., Proust-Lima, C., Le Gouge, A., Dartigues, J.F., Barberger-Gateau, P., Flavonoid intake and cognitive decline over a 10-year period. American journal of epidemiology, 165 (12), 1364-1371, 2007.

[30] Shaodong, C., Haihong, Z., Manting, L., Guohui, L., Zhengxiao, Z., \& Zhang, Y. M., Research of influence and mechanism of combining exercise with diet control on a model of lipid metabolism rat induced by high fat diet. Lipids health disease, 12, 21, 2013.

[31] Wise, L.E., Long, K.A., Abdullah, R.A., Long, J.Z., Cravatt, B.F., Lichtman, A.H., Dual fatty acid amide hydrolase and monoacylglycerol lipase blockade produces THC-like Morris water maze deficits in mice. ACS chemical neuroscience, 3 (5), 369-378, 2012. 
[32] Mustroph, M.L., Chen, S., Desai, S.C., Cay, E.B., DeYoung, E.K., Rhodes, J.S., Aerobic exercise is the critical variable in an enriched environment that increases hippocampal neurogenesis and water maze learning in male C57BL/6J mice. Neuroscience, 219, 62-71, 2012.

[33] Harnafi, H., Ramchoun, M., Tits, M., Wauters, J.N., Frederich, M., Angenot, L., \& Amrani, S., Phenolic acid-rich extract of sweet basil restores cholesterol and triglycerides metabolism in high fat diet-fed mice: A comparison with fenofibrate. Biomedicine \& preventive nutrition, 3 (4), 393-397, 2013.

[34] Zhang, X.L., Jiang, B., Li, Z.B., Hao, S., \& An, L.J., Catalpol ameliorates cognition deficits and attenuates oxidative damage in the brain of senescent mice induced by D-galactose. Pharmacology biochemistry and behavior, 88 (1), 64-72, 2007.

[35] Ōyanagui, Y., Reevaluation of assay methods and establishment of kit for superoxide dismutase activity. Analytical biochemistry, 142 (2), 290-296, 1984.

[36] Hao, W., Liu, Y., Liu, S., Walter, S., Grimm, M.O., Kiliaan, A.J., Fassbender, K., Myeloid differentiation factor 88-deficient bone marrow cells improve Alzheimer's disease-related symptoms and pathology. Brain, 134 (1), 278-292, 2011.

[37] Yim, C.Y., Soczynska, J.K., Kennedy, S.H., Woldeyohannes, H.O., Brietzke, E., McIntyre, R.S., The effect of overweight/obesity on cognitive function in euthymic individuals with bipolar disorder. European psychiatry, 27(3), 223-228, 2012.

[38] Kosari, S., Badoer, E., Nguyen, J.C., Killcross, A.S., Jenkins, T.A., Effect of western and high fat diets on memory and cholinergic measures in the rat. Behavioural brain research, 235(1), 98-103, 2012.

[39] Li, J., Wang, C., Zhang, J.H., Cai, J.M., Cao, Y.P., Sun, X.J., Hydrogen-rich saline improves memory function in a rat model of amyloid-beta-induced Alzheimer's disease by reduction of oxidative stress. Brain research, 1328, 152-161, 2010.

[40] Yu, H., Bi, Y., Ma, W., He, L., Yuan, L., Feng, J., Xiao, R., Longterm effects of high lipid and high energy diet on serum lipid, brain fatty acid composition, and memory and learning ability in mice. International journal of developmental neuroscience, 28 (3), 271-276, 2010

[41] Valls-Pedret, C., Lamuela-Raventós, R.M., Medina-Remón, A., Quintana, M., Corella, D., Pintó, X., Ros, E., Polyphenol-rich foods in the Mediterranean diet are associated with better cognitive function in elderly subjects at high cardiovascular risk. Journal of Alzheimer's disease, 29 (4), 773-782, 2012.

[42] Spencer, J.P., Vauzour, D., Rendeiro, C., Flavonoids and cognition: the molecular mechanisms underlying their behavioural effects. Archives of biochemistry and biophysics, 492 (1), 1-9, 2009.

[43] Papandreou, M.A., Dimakopoulou, A., Linardaki, Z.I., Cordopatis, P., Klimis-Zacas, D., Margarity, M., Lamari, F.N., Effect of a polyphenol-rich wild blueberry extract on cognitive performance of mice, brain antioxidant markers and acetylcholinesterase activity. Behavioural brain research, 198 (2), 352-358, 2009.

[44] Martinello, F., Soares, S.M., Franco, J.J., Santos, A.C., Sugohara, A., Garcia, S.B., \& Uyemura, S.A., Hypolipemic and antioxidant activities from Tamarindus indica L. pulp fruit extract in hypercholesterolemic hamsters. Food and chemical toxicology, 44 (6), 810-818, 2006.

[45] Chung, M.J., Sung, N.J., Park, C.S., Kweon, D.K., Mantovani, A., Moon, T.W., \& Park, K.H., Antioxidative and hypocholesterolemic activities of water-soluble puerarin glycosides in HepG2 cells and in C57 BL/6J mice. European journal of pharmacology, 578 (2), 159-170, 2008.

[46] Yang, R., Le, G., Li, A., Zheng, J., \& Shi, Y., Effect of antioxidant capacity on blood lipid metabolism and lipoprotein lipase activity of rats fed a high-fat diet. Nutrition, 22 (11), 1185-1191, 2006.

[47] Elias, M.F., Elias, P.K., Sullivan, L.M., Wolf, P.A., D'agostino, R.B., Lower cognitive function in the presence of obesity and hypertension: the Framingham heart study. International journal of obesity, 27 (2), 260-268, 2003.

[48] Farr, S.A., Yamada, K.A., Butterfield, D.A., Abdul, H.M., Xu, L., Miller, N.E., Morley, J.E., Obesity and hypertriglyceridemia produce cognitive impairment. Endocrinology, 149 (5), 2628-2636, 2008.

[49] Butterfield, D.A., Drake, J., Pocernich, C., Castegna, A., Evidence of oxidative damage in Alzheimer's disease brain: central role for amyloid $\beta$-peptide. Trends in molecular medicine, 7(12), 548-554, 2001.

[50] Khan, R.A., Khan, M.R., Sahreen, S., Protective effects of rutin against potassium bromate induced nephrotoxicity in rats. BMC complementary and alternative medicine, 12 (1), 204, 2012.

[51] Zhang, X.L., Jiang, B., Li, Z.B., Hao, S., An, L.J., Catalpol ameliorates cognition deficits and attenuates oxidative damage in the brain of senescent mice induced by D-galactose. Pharmacology biochemistry and behavior, 88 (1), 64-72, 2007.

[52] Fukuda, T., Ito, H., \& Yoshida, T., Antioxidative polyphenols from walnuts ( $<i>$ Juglans regia $</ i>$ L.). Phytochemistry, 63 (7), 795-801, 2003.

[53] Pribis, P., Bailey, R.N., Russell, A.A., Kilsby, M.A., Hernandez, M., Craig, W.J., \& Sabate, J., Effects of walnut consumption on cognitive performance in young adults. British journal of nutrition, 107 (09), 1393-1401, 2012.

[54] Poulose, S.M., Miller, M.G., \& Shukitt-Hale, B., Role of walnuts in maintaining brain health with age. The journal of nutrition, 144 (4), 561S-566S, 2014.

[55] Shabani, M., Nazeri, M., Parsania, S., Razavinasab, M., Zangiabadi, N., Esmaeilpour, K., \& Abareghi, F., Walnut consumption protects rats against cisplatin-induced neurotoxicity. Neurotoxicology, 33 (5), 1314-1321, 2012.

[56] Ramassamy, C., Emerging role of polyphenolic compounds in the treatment of neurodegenerative diseases: a review of their intracellular targets. European journal of pharmacology, 545 (1), 51-64, 2006.

[57] Moreira, E.L.G., Aguiar Jr, A.S., de Carvalho, C.R., Santos, D.B., de Oliveira, J., de Bem, A.F., Prediger, R.D., Effects of lifestyle modifications on cognitive impairments in a mouse model of hypercholesterolemia. Neuroscience letters, 541, 193-198, 2013.

[58] Umeda, T., Tomiyama, T., Kitajima, E., Idomoto, T., Nomura, S., Lambert, M.P., Mori, H., Hypercholesterolemia accelerates intraneuronal accumulation of $A \beta$ oligomers resulting in memory impairment in Alzheimer's disease model mice. Life sciences, 91 (23), 1169-1176, 2012. 